\title{
Corruption, Political Competition and Environmental Policy
}

\author{
John Wilson \\ University of Adelaide, South Australia \\ Email: john.wilson@adelaide.edu.au \\ Phone: (08)8303 4926 \\ Richard Damania \\ University of Adelaide, South Australia \\ Email: richard.damania@adelaide.edu.au \\ Phone: (08)8303 4933
}

\begin{abstract}
There is a vast literature on the causes and consequences of corruption. A common theme is the belief that countries which exhibit a low level of political competition are more likely to have higher levels of corruption. The model presented here examines the effect of corruption on environmental policy under varying degrees of political competition. An important feature of this model, which has received far less attention in the literature, is that corruption may occur at different levels. A polluting firm attempts to reduce the amount of an environmental tax it pays by bribing a low level bureaucrat to make false reports regarding emission levels. In addition, it also makes contributions to the incumbent and rival parties of government in order to influence key policy parameters. The model thus provides a picture of the relationship between political competition, environmental outcomes and the type of corruption which may be observed. It is shown that higher levels of political competition result in more stringent regulations and better environmental outcomes. Political competition also has the capacity to reduce both grand and petty corruption, however, this is not assured. The model also suggests that polluting interests may have an incentive to corrupt opposition parties in order to weaken their political position. This may lead to policy convergence even when political competition is strong. Political competition is indicated as a necessary but not sufficient means by which to combat corruption.
\end{abstract}

(C) 2003, John Wilson, University of Adelaide 


\section{Introduction}

Corruption, defined by the World Bank (1997) as 'the use of public office for private gain' has been receiving increased attention in the literature. Corruption has been associated with lower economic growth (Mauro, 1995; World Bank 1997, RoseAckerman, 1999; Easterly and Levine, 1997), lower foreign investment (Wei, 1997, Hines, 1995) and is said to undermine the effect of economic policies.

There are several papers which examine the causes of corruption. A common theme is that a major determinant of corruption is the lack of political accountability of policy makers. In an empirical evaluation, Treisman (2000) notes this (via the proxy of 'the political system') as one of the major long term determinants. Rose Ackerman (1999) and World Bank $(1997,2000)$ also note the importance of this variable. Johnston (1999) examines the inverse link between corruption and the level of democracy, arguing that a more competitive political system is a necessary condition for corruption reforms to succeed. The rationale for the link between corruption and democracy is that increased political competition forces politicians to consider the public interest to a greater degree. Alternately, it can be considered as raising the costs of being corrupt. Further, by fostering the development of strong opposition parties, political competition can serve as a device by which entrenched corruption is exposed.

In an environmental context, there is evidence to suggest that the large rents associated with resource exploitation provide scope for corruption and the environmental consequences of this may be large (World Bank, 1997). Callister (1999) provides an extensive list of activities which may be considered corruption occurring in the forestry sector. Examples include the logging of timber species protected by law and extracting more timber than authorised. She goes on further to distinguish between levels of corruption. This is something which, to date, has received far less attention in the literature. Pope (1996) discusses the case of 'grand' and 'petty' corruption. The former involves giving a bribe to a high ranking official, which the latter involves payments to junior bureaucrats. A more comprehensive type 
of definition is provided by the World Bank (2000) in their discussion of state capture and administrative corruption. The former is defined as the payment of a bribe to influence the setting of a policy parameter, while the latter involves payment to distort the implementation of existing laws. In the environmental context, an example of state capture provided by Callister (1999) is the paying of senior politicians to obtain timber concessions. Payments made to bureaucrats to under-report the amount of harvesting fall into the category of administrative corruption.

This paper examines the effects of political competition on the level of corruption in the context of an environmental policy setting. While there is general acceptance in the literature that such competition reduces corruption, there is little formal modelling to back this assertion up. Further, the issue of hierarchical corruption is often completely ignored.

The model presented here details the setting of environmental policy in the presence of corruption. A polluting firm is able to minimise its obligations under the policy by making contributions to political parties (grand corruption) or by bribing an emissions inspector to under-report emission levels (petty corruption). The model presented here is a synthesis of earlier work by Grossman and Helpman $(1994,1996)$ and Mookherjee and Png (1995).

Mookherjee and Png (1995) present a model which considers the discharge of pollution into a sewer system. The relevant authority imposes fines for the discharge of waste but must rely on the services of an inspector to monitor the level of effluent entering the sewer. This provides scope for corruption as the polluting firm can bribe the inspector to under-report. The authors examine the relationship between fines and the level of corruption, showing that while large increases in penalties generally reduce corruption, smaller increases may actually increase it. This model forms the basis for the analysis of petty corruption in this paper.

Grossman and Helpman (1994), building on earlier work by Bernheim and Whinston (1986), present a model in which trade policy is influenced by representative special 
interest groups. In their paper, government trades off the welfare of the public at large with the private benefits that accrue from contributions made by the special interest groups. Importantly, the relative importance of contributions to aggregate welfare is determined by an exogenous weight. Grossman and Helpman discuss the possible motives of making campaign contributions as an 'electoral motive', in which the lobby group seeks to influence the outcome of the political process and the 'influence motive' in which the aim is to change the policy of the recipient government. Their focus is on this latter motivation. Grossman and Helpman (1996) extends the model to allow for political competition between political parties. This model, like those of Austen Smith (1987) and Baron (1994), allows for the possibility that monetary contributions offered by special interest groups can actually alter election outcomes. In Austen Smith (1987) such funds are used by politicians to alleviate voter concerns over policy. Baron (1994) allows for campaign funding to have a direct effect on voter behaviour. In their paper, Grossman and Helpman also allow campaign funds to influence voter behaviour, but also allow for policies to be pliable contingent on the contributions received. In this way they are able to examine both the electoral and influence motives of special interests in making contributions.

This paper uses the framework of Grossman and Helpman (1994) to model 'grand corruption'. This paper differs somewhat from their analysis where payments made to political parties are not expressly considered to be a form of corruption. In the current model, there are two political parties who take part in a battle for political control. Unlike Grossman and Helpman (1996), contributions received by political parties do not influence the outcome of the political struggle.

The focus of the model is to evaluate the effects of political competition on environmental and policy outcomes, as well as levels of both petty and grand corruption. It is shown that increasing political competition, while yielding better environmental outcomes, may not reduce corruption at either level. In particular, a reduction in grand corruption is contingent on how large a welfare issue environmental damage is, while petty corruption can only be reduced when the enforcement infrastructure is strong. The model also reveals that polluting interests 
may face an incentive to pay bribes to opposition parties in an attempt to make policies converge. This tempers the potential policy improvements that may result from political competition. Thus, contributions from polluting interests can actually constrain and corrupt the political process.

The remainder of this paper is organised as follows: section 2 provides an overview of the model and derives the equilibrium properties. In section 3, comparative static analysis is undertaken to enable the effects of political competition to be examined. Section 4 provides some concluding remarks and discussion. 


\section{The Model}

\subsection{Overview}

A single firm discharges pollution, which is controlled through an emissions tax. The tax is administered by potentially corruptible environmental inspectors. There are two competing political parties: the incumbent government and a rival opposition party. In order to influence environmental regulations, the firm offers each party a bribe schedule which is contingent upon the policies chosen. Once policies have been announced, there is an election, the outcome of which is partly contingent upon the policies of each party. Given a knowledge of these policies, the firm and inspector interact and bargain over the level of compliance and the bribe that will be paid. Figure 1 provides an overview of the game and the sequence of events. The model is solved by backwards induction, hence we begin by describing the firm inspector interaction.

\section{$\underline{2.2 \text { Firm - Inspector Interaction }}$}

Consider a firm $(f)$ which as a result of its production process, discharges emissions(e). These emissions result in environmental damage $(D(e))$, with $D^{\prime}(e)>0$ and $D^{\prime \prime}(e)>0$. For simplicity, production costs are assumed to be zero.

In order to combat the problem of environmental damage, the government can levy a $\operatorname{tax}(t)$ on each unit of emissions. An informational asymmetry exists such that the government must rely on the services of an inspector $(m)$ to report pollution levels. In return for a fixed wage $(w)$, the inspector ascertains the level of emissions of the firm and conveys this information to the government. The tax is thus levied on the level of emissions reported by the inspector.

In order to reduce its tax burden, the firm may offer a bribe to the inspector to induce her to report some level of emissions $(\hat{e})$ which is lower than the true level $(e)$. This form of corruption is referred to in this paper as 'petty' corruption. The level of under-reporting is defined by $v=(e-\hat{e}), \hat{e} \leq e$. 
The government can commission an audit which successfully uncovers the true level of emissions. The probability of being audited is given as $\lambda(\hat{e}), \lambda \in(0,1)$, with, $\partial \lambda / \partial \hat{e}^{<0} ; \partial^{2} \lambda / \partial \hat{e}^{2}>0$. Note that the probability of being audited is ceteris paribus higher (lower) when the level of reported emissions is lower (higher). This implies that when the level of reported emissions is low, the government suspects there to be a greater probability that the firm is evading the tax. The relationship between the audit rate and the level of reported emissions can be thought of as the 'audit policy rule'.

Once undertaken, an audit always uncovers the actual level of emissions. If the inspector and the firm have conspired to under-report, each is fined at the rate of $\theta$.

The expected fine payable is:

$$
E\left(F^{g}\right)=\lambda(\hat{e}) h\left(\theta^{\mathrm{g}}, v\right) \quad g=(f, m)
$$

It is assumed that $\partial h / \partial \theta>0, \partial^{2} h / \partial \theta^{2}>0 ; \partial h / \partial v>0, \partial^{2} h / \partial v^{2}>0$. The latter of these assumptions captures the idea that penalties increase in severity when the level of under-reporting is greater (i.e. 'the punishment fits the crime').

We begin by establishing the equilibrium bribe and reported level of emissions. In considering its prospective bribe, the firm must consider the benefits from reducing its tax burden and the expected costs of non-compliance. Let gross profits when a bribe is paid be given by $G(e)=P(e) e$, where $P$ is the price of the good. ${ }^{1}$ If the firm decides to comply and correctly report emissions, gross profit is given by $G\left(e^{h}\right)=P\left(e^{h}\right) e^{h}$. The expected gain from bribery can be written:

$$
\Psi^{f}=\left[G(e)-\left(B+t \hat{e}+\lambda h^{f}\left(\theta^{f}, v\right)\right)\right]-\left[G\left(e^{h}\right)-t e^{h}\right]
$$

\footnotetext{
${ }^{1}$ Notice that production and abatement costs are ignored and one unit of output results in one unit of emissions.
} 


\section{Figure 1 - Game Tree}

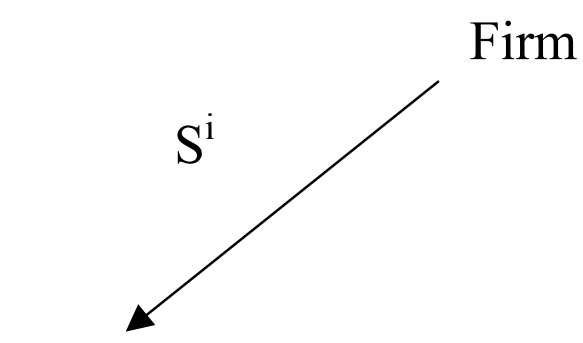

Party i

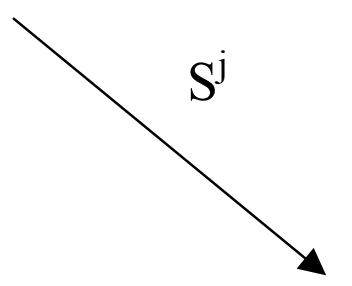

Party j
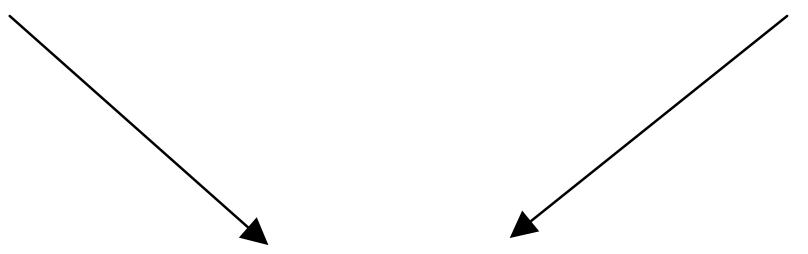

Policy Announcements $\left(\mathrm{t}^{\mathrm{i}}, \theta^{\mathrm{i}}\right.$ and $\left.\mathrm{t}^{\mathrm{j}}, \theta^{\mathrm{j}}\right)$

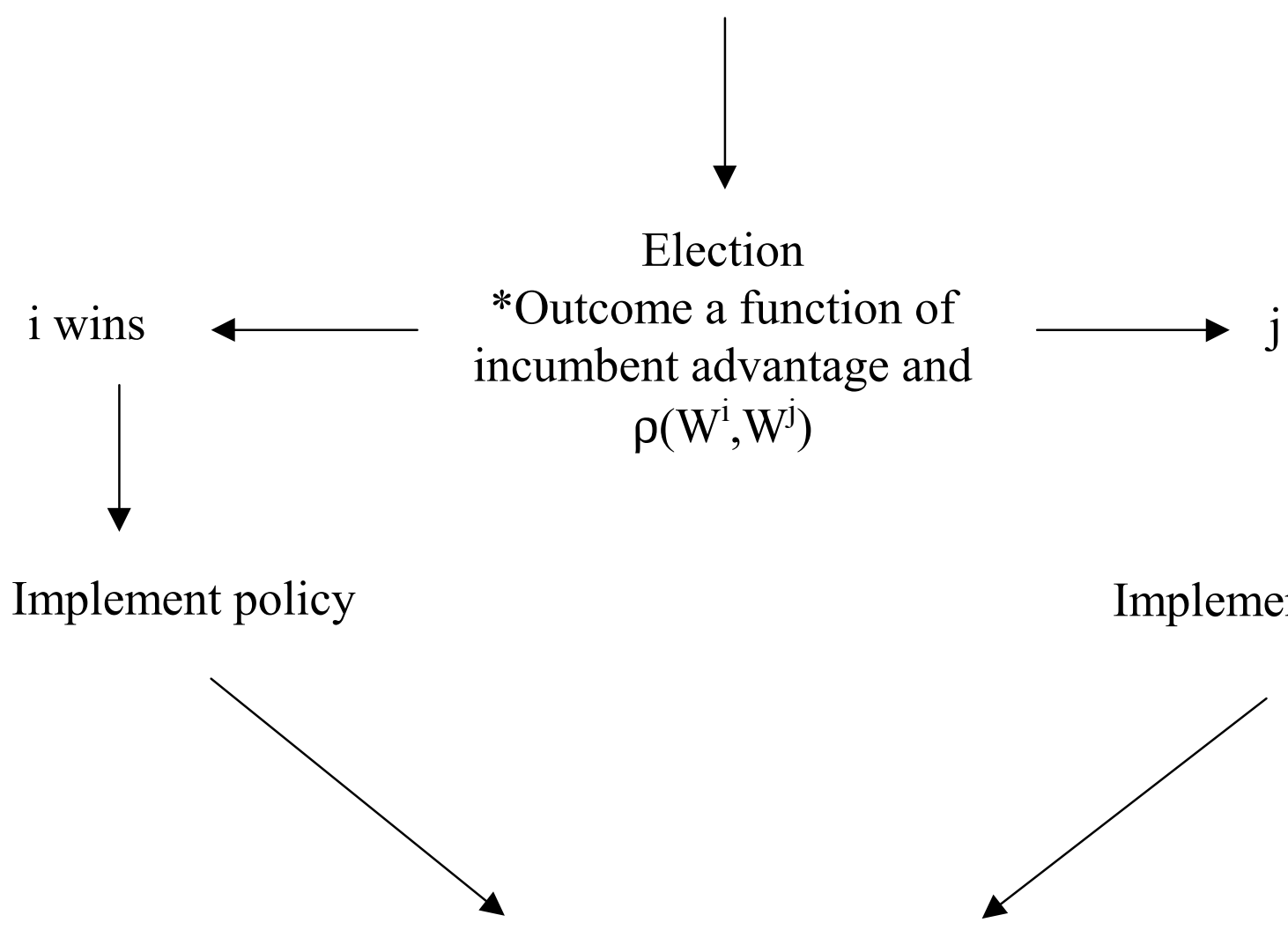

Firm -Inspector interaction 
Where the first term represents the expected net profits when a bribe is offered and the second term represents net profits when the inspector makes a truthful report regarding emission levels. ${ }^{2}$

The inspector faces a similar trade off. If she accepts a bribe, her expected gain is,

$$
\Psi^{m}=\left[w+B-\lambda h^{m}\left(\theta^{m}, v\right)\right]-w
$$

In this stage of the game, backward induction allows us to take the tax and penalty rates as given. Reported and actual emissions are chosen to maximise the expected joint payoffs from the bribe:

$$
\underset{\hat{\mathrm{e}}}{\operatorname{Max}} \mathbf{J} \equiv\left(\Psi^{f}+\Psi^{m}\right)
$$

The first order conditions are:

$$
\begin{aligned}
& \frac{\partial \mathrm{J}}{\partial \hat{\mathrm{e}}}=-\mathrm{t}+\lambda \frac{\partial h^{T}(\theta, v)}{\partial v}-\frac{\partial \lambda}{\partial \hat{e}} h^{T}(\theta, v)=0 \\
& \frac{\partial \mathrm{J}}{\partial \mathrm{e}}=\frac{\partial \mathrm{G}(\mathrm{e})}{\partial \mathrm{e}}-\lambda \frac{\partial h^{T}(\theta, v)}{\partial v}=0
\end{aligned}
$$

Where $h^{T}=h^{f}+h^{m}$. Note that equation (3a) specifies that in equilibrium, reported emissions will be set to equate the marginal cost of compliance and the marginal expected cost of non-compliance.

The equilibrium bribe is determined by a Nash bargain between the firm and the inspector, where both are assumed to have equal bargaining power. This implies that

\footnotetext{
${ }^{2}$ For notational brevity, the arguments of $\lambda$ are ignored.
} 
the firm and the inspector share equally the benefits from corruption. The bribe follows the Nash bargain,

$$
\underset{\mathrm{B}}{\operatorname{Max}}\left(\Psi^{f} \Psi^{m}\right)
$$

Using (1a) and (1b), the equilibrium bribe is given as:

$$
\mathrm{B}=\frac{1}{2}\left[\mathrm{G}(\mathrm{e})-\mathrm{G}\left(\mathrm{e}^{\mathrm{h}}\right)+\mathrm{t}\left(\mathrm{e}^{\mathrm{h}}-\hat{\mathrm{e}}\right)-\lambda\left(h^{f}\left(\theta^{f}, v\right)-h^{m}\left(\theta^{m}, v\right)\right)\right]
$$

Of interest is the observation that an increase in the marginal fine on the inspector may increase the level of the bribe. To see this, consider the case where the marginal fine increases and $\partial h^{f} / \partial \theta^{f}<\partial h^{m} / \partial \theta^{m}$. Provided (1a) remains positive, the firm will simply offer a larger bribe to the inspector in order to compensate her for the greater expected loss. ${ }^{3} \quad$ To ensure that raising the marginal fine always reduces the equilibrium bribe, it is assumed that $\partial h^{f} / \partial \theta^{f}>\partial h^{m} / \partial \theta^{m}$. This assumption requires $h^{f}\left(\theta^{f}, v\right)-h^{m}\left(\theta^{m}, v\right)>0$, thereby implying that penalties on the bribe giver are more severe than on the recipient.

Appendix A provides some useful equilibrium properties of firm - inspector interaction. Summarising, it is shown that (i) an increase in the tax rate will reduce the level of emissions (property 2) but, (ii) increase the level under-reporting (property 3), (iii) An increase in the fine decreases the level of emissions (property 5) and (iv) an increase in the fine will reduce the level of under-reporting (property 6).

\section{$\underline{2.3 \text { Political Equilibrium }}$}

Having examined the firm-inspector outcome, attention is now turned towards the political equilibrium. As described earlier, this involves the firm offering political contributions in return for more favourable policy outcomes. Lobbying takes the form

\footnotetext{
${ }^{3}$ Raising the level of the marginal fine imposed on the bribe taker will only increase the equilibrium bribe provided (1a) remains positive. If $\theta$ is increased sufficiently, the inequality is overturned and the
} 
of offering political contributions $(S)$ to policy makers. While not an explicit arrangement, it is assumed that contributions induce the government to formulate policies that the firm finds more favourable. This is the case of 'grand' corruption. ${ }^{4}$ This stage of the game follows Bernheim and Whinston's (1986) menu auction model as applied by Grossman and Helpman (1994).

An important feature of this model is that the firm makes contributions to two political parties, the incumbent (i) and its rival (j). These parties announce policies which are partly contingent on the contributions received from the firm. Following the announcement of policies, a political competition ensues. The probability of the success or failure of each party is to some degree determined by the welfare implications of their policies. The policy dependent level of support for the incumbent is given by $\rho\left(W^{i}, W^{j}\right) \in(0,1)$. The incumbent may also hold an a priori advantage $(\alpha \in(0,1))$ which tempers the political effect of a policy. ${ }^{5}$ A high incumbency advantage lessens the relative importance of gaining support by adopting welfare enhancing policies. It is assumed that the victor of the political struggle faithfully implements its policies. ${ }^{6}$

Importantly, while political contributions convey private benefits to the recipients, it is assumed that campaign spending has no effect on the outcome of the political struggle. In the context of democratic elections, there is a large volume of empirical

firm no longer will be prepared to offer a bribe. In contrast, in the event that increasing the marginal fine does increase the equilibrium bribe, equation (1b) remains positive.

${ }^{4}$ It is important to note that in many countries, political contributions are not illegal and thus may not constitute corruption. Usually however, such contributions cannot legally be made with the expectation of favours from the recipient, nor can they be made clandestinely. In this paper, contributions are given specifically to obtain a more favourable policy outcome and are thus considered to be a form of corruption.

${ }^{5}$ In this model, the incumbent advantage is used to measure the ability of the current government to avoid the political effect of its policies. For example, it may measure the effectiveness of the incumbent in preventing certain groups from voting, or in rigging an election outcome. The notion also extends to countries with a fair and transparent democratic system. In such countries, one can consider the incumbency advantage as 'political bias' (i.e. the proportion of voters who vote for the incumbent regardless of its policies).

${ }^{6}$ An important side issue is the assumption that politicians do not renege on their promises. In a one shot game, there exists a motive to implement policies which diverge from those promised. This default could be against the firm (different policy once contributions are accepted) or against the public at large (different policy after the political struggle is fought and won). As noted by Grossman and Helpman 
work examining the effect of campaign spending on outcomes. Most find spending by the incumbent government has no significant effect on electoral prospects, but spending by challengers has a positive and significant effect on the chances of winning (e.g. Glantz et al (1976); Erikson and Palfrey (1993)). Levitt (1994) argues that when district specific effects are taken into account, campaign spending has no significant effect on the chances of victory for either type of candidate.

The government of the day sets the tax rate and the marginal fine for under-reporting. Announcements with regard to each policy are made to the public, prior to the political struggle. As noted, the outcome of this struggle depends in part on the levels of aggregate welfare implied by the policy platforms. Aggregate welfare is the sum of all agents utility on the model and is thus given: ${ }^{7}$

$$
W=\int_{0}^{e} P d e-D(e)-C(\theta)
$$

Where $C(\theta)$ represents the costs of administering the penalty and judicial regime with $\partial C / \partial \theta>0$ and $\partial^{2} C / \partial \theta^{2}>0$

In what follows, it is assumed that the tax rate and the fine rates are below their welfare maximising levels, hence:

$$
\frac{\partial W}{\partial t}=\left(P-\frac{\partial D}{\partial e}\right) \frac{\partial e}{\partial t}>0
$$

(1996), honestly implementing policies can be motivated in a repeated game where credible punishments are imposed on agents who break promises.

${ }^{7}$ Aggregate welfare is the sum of consumer surplus $\left(\int_{0}^{e} P(e) d e-P(e) e\right)$, the firm's profits $((P(e)-t) e)$, the

government's cost of imposing fines $(C(\theta))$ and environmental damage $(D(e))$. Taxes and contributions paid by the firm are received by the government, the wage received by the inspector is paid by the government and the firm pays bribes received by the inspector. These obviously cancel out in aggregate. 


$$
\frac{\partial W}{\partial \theta}=\left(P-\frac{\partial D}{\partial e}\right) \frac{\partial e}{\partial \theta}-\frac{\partial C}{\partial \theta}>0
$$

The expected utilities of the incumbent and rival political parties are given respectively as:

$$
\begin{aligned}
& E\left(U^{i}\right)=\left[\alpha+(1-\alpha) \rho\left(W^{i}, W^{j}\right)\right] R+S^{i} \\
& E\left(U^{j}\right)=\left[1-\left(\alpha+(1-\alpha) \rho\left(W^{i}, W^{j}\right)\right)\right] R+S^{j}
\end{aligned}
$$

Where $R$ denotes the exogenous returns to being in office, $S$ the contributions received from the firm and $\alpha \in(0,1)$ is a measure of incumbency advantage. ${ }^{9}$ The likelihood of the incumbent winning the political struggle is partially determined by the parameter $\rho \in(0,1)$. This is the policy determined component of political competition. Obviously, the importance of this parameter is lower when $\alpha$ is relatively high. Notice that the political parties are assumed to be completely malevolent: they care about aggregate welfare to the extent that it effects their political standing. Grossman and Helpman (1994) assume that the importance of aggregate welfare relative to campaign contributions is determined by an exogenous weight. This paper takes an important step in making the weight endogenous.

There is a significant literature regarding the nature of political competition (see for example: Downs (1957), Romer (1975), Johnson (1988), Grofman (1993), Roemer (2002)). In this paper, the exact details of the political struggle are not explicitly modelled. Instead, the following reasonable assumptions are made, which are consistent with the literature:

$$
\frac{\partial \rho}{\partial W^{i}}>0, \frac{\partial^{2} \rho}{\partial W^{i^{2}}}<0 \quad ; \frac{\partial \rho}{\partial W^{j}}<0, \frac{\partial^{2} \rho}{\partial W^{j^{2}}}>0
$$

\footnotetext{
${ }^{8}$ The inequality is maintained provided marginal environmental damage from a tax induced change in emissions is greater than the marginal effect on the profits of the firm from lost output.
} 
Summarising, the likelihood of the incumbent retaining power increases when it announces welfare improving policies and decreases when its rival does the same. Concavity of $\rho$ in $\mathrm{W}^{\mathrm{i}}$ (and convexity in $\mathrm{W}^{\mathrm{j}}$ ) captures the idea of diminishing marginal political returns to welfare enhancing policies.

For notational brevity, define $\Phi=\{t, \theta\}$ as the policy set. The conditions for an equilibrium in this type of game are set out in lemma 2 of Bernheim and Whinston (1986) and Grossman and Helpman (1994). In particular, the optimal policies satisfy the following criteria:

$\Phi^{K} \in \arg \max E\left(U^{k}\right) \quad K=i, j \quad i \neq j \quad \Phi=t, \theta$

$\Phi^{K} \in \arg \max U^{f}+E\left(U^{K}\right) \quad K=i, j \quad i \neq j \quad \Phi=t, \theta$

where,

$U^{f}=E(\Pi)-S^{K}$

where $\mathrm{E}(\Pi)$ represents the firms expected profits gross of contributions:

$$
E(\Pi)=\left(\alpha+(1-\alpha) \rho\left(W^{i}, W^{j}\right)\right) \Pi^{i}\left(\Phi^{i}\right)+\left[1-\left(\alpha+(1-\alpha) \rho\left(W^{i}, W^{j}\right)\right)\right] \Pi^{j}\left(\Phi^{j}\right)
$$

$\Pi$ is defined as:

$$
\Pi=P(e) e-t \hat{e}-B-\lambda f^{f}(\theta, v)
$$

and the superscripts denote profits implied by the policy announcements of parties $i$ and $\mathrm{j}$ respectively. (BW1) implies the equilibrium tax rate satisfies the condition that each political party chooses $\Phi$ to maximise its expected utility given the offered

\footnotetext{
${ }^{9}$ For simplicity, $\mathrm{R}$ is normalised to zero when in opposition.
} 
contributions from the firm. (BW2) requires that the joint utilities of the firm and the political parties are maximised. Maximising (BW1) yields the following first order conditions:

$$
\begin{array}{ll}
\frac{\partial E\left(U^{i}\right)}{\partial \Phi^{i}}=(1-\alpha) \frac{\partial \rho}{\partial W^{i}} \frac{\partial W^{i}}{\partial \Phi^{i}} R+\frac{\partial S^{i}}{\partial \Phi^{i}}=0 & \Phi=t, \theta \\
\frac{\partial E\left(U^{j}\right)}{\partial \Phi^{j}}=(\alpha-1) \frac{\partial \rho}{\partial W^{j}} \frac{\partial W^{j}}{\partial \Phi^{j}} R+\frac{\partial S^{j}}{\partial \Phi^{j}}=0 & \Phi=t, \theta
\end{array}
$$

(BW2) implies,

$$
\frac{\partial E(\Pi)}{\partial \Phi^{K}}-\frac{\partial S^{K}}{\partial \Phi^{K}}+\frac{\partial E\left(U^{i}\right)}{\partial \Phi^{i}}+\frac{\partial E\left(U^{j}\right)}{\partial \Phi^{j}}=0 \quad K=i, j \quad i \neq j \quad \Phi=t, \theta
$$

Substituting the left hand side of (9a) and (9b) into the right hand side of (9c) and rearranging yields,

$$
\frac{\partial E(\Pi)}{\partial \Phi^{K}}=\frac{\partial S^{K}}{\partial \Phi^{K}} \quad K=i, j \quad i \neq j \quad \Phi=t, \theta
$$

Equation (9d) asserts in equilibrium contributions are offered to the point where the change in the firms contribution equals the marginal effect of a change in policy on expected profits. This type of contribution schedule is coined locally truthful by Grossman and Helpman (1994).

The firm chooses contribution schedules in order to maximise equation (8a). The first order conditions are: 


$$
F_{i}=(\alpha+(1-\alpha) \rho) \frac{\partial \Pi^{i}}{\partial \Phi^{i}} \frac{\partial \Phi^{i}}{\partial S^{i}}+(1-\alpha) \frac{\partial \rho}{\partial W^{i}} \frac{\partial W^{i}}{\partial \Phi^{i}} \frac{\partial \Phi^{i}}{\partial S^{i}}\left(\Pi^{i}-\Pi^{j}\right)-1=0 \quad \Phi=t, \theta
$$

$$
F_{j}=[1-(\alpha+(1-\alpha) \rho)] \frac{\partial \Pi^{j}}{\partial \Phi^{j}} \frac{\partial \Phi^{j}}{\partial S^{j}}+(1-\alpha) \frac{\partial \rho}{\partial W^{j}} \frac{\partial W^{j}}{\partial \Phi^{j}} \frac{\partial \Phi^{j}}{\partial S^{j}}\left(\Pi^{i}-\Pi^{j}\right)-1=0 \quad \Phi=t, \theta
$$

Rearranging, we obtain the local truthfulness conditions:

$$
\begin{aligned}
& \frac{\partial S^{i}}{\partial \Phi^{i}}=(\alpha+(1-\alpha) \rho) \frac{\partial \Pi^{i}}{\partial \Phi^{i}}+(1-\alpha) \frac{\partial \rho}{\partial W^{i}} \frac{\partial W^{i}}{\partial \Phi^{i}}\left(\Pi^{i}-\Pi^{j}\right) \\
& \frac{\partial S^{j}}{\partial \Phi^{j}}=[1-(\alpha+(1-\alpha) \rho)] \frac{\partial \Pi^{j}}{\partial \Phi^{j}}+(1-\alpha) \frac{\partial \rho}{\partial W^{j}} \frac{\partial W^{j}}{\partial \Phi^{j}}\left(\Pi^{i}-\Pi^{j}\right)
\end{aligned}
$$

Note that for contributions to be made, the firm must receive a benefit by way of less stringent policy. This requires $\partial S / \partial \Phi<0$.

Equations (10c) and (10d) suggest there to be two components to contributions made by the firm. The first is the incentive to induce the recipient to adopt a less stringent policy platform. This obviously has the effect of increasing profits realised in the event that the party in question is in power. The second component is derived from the fact that a change in policy which favours the firm comes at a political cost. The second term in each expression reveals how much of the contribution goes towards compensating the parties for the political costs of adopting a less popular policy position. This compensation requirement can be thought of as reducing the marginal product of contributions from the perspective of the firm. Political competition thus

\footnotetext{
${ }^{10}$ The arguments of $\rho$ are ignored for notational brevity.
} 
has the capacity to reduce the marginal productivity of contributions. This issue is discussed at greater length later in the paper.

The first order conditions of the political parties are given by (9a) and (9b):

$$
\begin{aligned}
& \frac{\partial E\left(U^{i}\right)}{\partial \Phi^{i}}=(1-\alpha) \frac{\partial \rho}{\partial W^{i}} \frac{\partial W^{i}}{\partial \Phi^{i}} R+\frac{\partial S^{i}}{\partial \Phi^{i}}=0 \\
& \frac{\partial E\left(U^{j}\right)}{\partial \Phi^{j}}=(\alpha-1) \frac{\partial \rho}{\partial W^{j}} \frac{\partial W^{j}}{\partial \Phi^{j}} R+\frac{\partial S^{j}}{\partial \Phi^{j}}=0
\end{aligned}
$$

Equations (9a) and (9b) imply that in equilibrium, the parties must trade off the effects of a policy change on political contributions against the electoral consequences.

\section{Equilibrium Properties}

In this section, the comparative static analysis of the political equilibrium is presented and discussed. We examine in particular how the level of contributions and policy platforms of the parties change when the level of political competition changes. The parameter $\alpha$ is a measure of incumbency advantage. When $\alpha$ is large, the incumbent can avoid the political effects of its policies. This parameter is thus used as a proxy for the level of political competition, with lower levels implying a more competitive environment. Using the results in Appendix A, the effect of political competition on the level of petty corruption is also examined. All proofs are presented in Appendix B.

\section{Lemma 1}

If the returns to holding a government position $(R)$ are sufficiently large, an increase in incumbency advantage $(\alpha)$ results in both parties announcing less stringent policies.

$$
\frac{d \Phi^{i}}{d \alpha}<0 \quad \frac{d \Phi^{j}}{d \alpha}<0 \quad \Phi=t, \theta
$$


The intuition for this result is straightforward. As the incumbency advantage grows, there is less political competition. Hence the political cost of lowering the stringency of environmental controls falls. As a result, each of the political parties has less incentive to adopt welfare improving policies. An alternative (yet consistent) way of expressing this intuitive result is that as the parties are completely malevolent and only care about welfare from the perspective of political gain, a higher incumbency advantage lowers the importance of improving welfare compared with procuring contributions from the firm.

When the marginal costs associated with administering fines are large, then an increase in incumbency advantage leads to a greater change in the tax rate than in the fine.

$\left|\frac{d t}{d \alpha}\right|>\left|\frac{d \theta}{d \alpha}\right| \quad$ when $\quad \frac{\partial \mathrm{C}(\theta)}{\partial \theta} \quad$ is large

To understand this result, it helps to consider once again the incentives facing each political party. Recall from equations (7c) and (7d) that each party derives no direct utility from improving the welfare of the public at large. It is only because the public have some role in determining the outcome of the political struggle that the parties consider their interests. That said, we can see from equations (7a) and (7b) that the welfare effects of each policy instrument will not be the same. Importantly, there are costs associated with the implementation of fines for petty corruption which temper the welfare gain. There are no such costs associated with the tax. ${ }^{11}$ This implies that the political implications of the two instruments are not the same: in particular, if the costs of imposing fines are large, the tax rate will have a greater impact and thus be subject to a greater adjustment when incumbency advantage changes.

\footnotetext{
${ }^{11}$ This obviously makes the very simplified assumption that collection of taxes is done at zero cost. In reality this would not be the case. The argument presented here depends on tax collection costs being less than the costs associated with the imposition of the fine, not on tax collection costs being zero.
} 


\section{Lemma 2}

An increase in political competition results in a decrease in the level of emissions and thus brings about better environmental outcomes, $\quad \frac{d e}{d \alpha}<0$.

An increase in political competition results in more stringent policy in terms of both the marginal fine and the tax rate. This raises the costs of polluting for the firm. As such, we see the level of emissions fall.

\section{Lemma 3}

When political competition $(\alpha)$ increases, the effect on compliance levels is ambiguous: $\quad \frac{d v}{d \alpha}<0$

An increase in political competition leads to a higher tax rate and a higher marginal fine. Higher taxes increase the benefits from under-reporting emissions. However, at the same time an increase in the marginal fine increases the expected costs of petty corruption, thereby increasing reported emissions. As these effects work in opposite directions, the overall effect of an increase in the level of political competition is ambiguous.

For completeness, Appendix B details conditions under which greater political competition leads to higher levels of petty corruption. This can only occur when the enforcement mechanisms are weak. In particular, when the audit policy rule is lax (decreased reporting does not induce a strong increase in audit rate), when the marginal punishment does not rise sufficiently with the severity of the crime, and when the probability of being audited is so low that raising the fine is not an efficient deterrent, petty corruption will increase.

The intuition for this is simply that under a regime of weak enforcement, the marginal effects of a change in the punishment are small. The benefits of evading the (now higher) tax are, in this case, greater than the expected costs of criminal activity. 


\section{Proposition 1a}

When environmental damage is a sufficiently large welfare issue, the firm will make greater contributions to the party it would least prefer to see in power.

The intuition behind this seemingly counter-intuitive result is that the firm must consider the political effects of the contributions it makes. For example, suppose that environmental damage is a large welfare issue and that the incumbent party announces a less stringent policy. ${ }^{12}$ Clearly, the firm will do better under party $i$. The rival can increase its chances of gaining power by announcing more stringent emission controls. To prevent such an outcome, the firm makes higher contributions to the rival, thus ensuring that political competition does not lead to policy improvements.

In general, the sign of $d S^{i} / d \alpha$ is ambiguous. However, there are some circumstances where the sign can be determined. In the following proposition, it is assumed that party $i$ announces less stringent policy than its rival, hence $\Pi^{i}-\Pi^{j}>0$.

\section{Proposition $1 b$}

As incumbency advantage increases (or political competition declines), the firm makes higher contributions to the incumbent: $\quad \frac{d S^{i}}{d \alpha}>0$

As the incumbent becomes more certain of holding power, the political cost of adopting welfare reducing policies falls. The firm thus no longer has to compensate party $\mathrm{i}$ for the political cost of such policies. This implies that the marginal productivity of those contributions is higher, hence the firm is more prepared to pay more.

When incumbency advantage increases (or political competition declines), the effect on contributions to the rival is ambiguous: $\frac{d S^{j}>}{d \alpha<}<$ :

\footnotetext{
${ }^{12}$ The opposite result applies in the case that party $\mathrm{j}$ offers the less stringent policy.
} 
(a)If the marginal political effect of a change in the rival's policy is sufficiently large, the firm will increase contributions to the rival

(b) If the marginal political effect of a change in the rival's policy is relatively small, contributions will fall.

When incumbency bias increases, the firm increases contributions to party i. This induces the incumbent to adopt a less stringent set of policies. In considering payments to the rival in these circumstances, the firm must consider the political effects of abandoning the rival. For instance, if payments to the rival are decreased, policies of the rival will be more stringent and closer to the welfare maximising level, thus increasing the probability that the rival wins office. In such an event, the firm has an incentive to increase contributions to the rival. This can be interpreted as a strategy by the firm to weaken the opposition to its more favoured party. Conversely, if the public at large do not care about the policy issue, then abandoning the rival in favour of the stronger incumbent is optimal as the risk of the rival capitalising on any policy divergence is small. In such circumstances, payments to the rival will fall when incumbency bias increases.

This concept can be clarified by a simple example. Suppose we have an undemocratic regime in which the incumbent has complete control over power $(\alpha=1)$. Also assume that emission levels cause a large amount of environmental damage. This implies that pollution is a large welfare issue. Because there is effectively no opposition, the party $\mathrm{i}$ incurs no political cost from adopting welfare reducing policies. Further, as there is no political cost, the firm's contributions are at their most productive. There is no incentive to give any contributions to the rival government.

However, now suppose that that the control over power is no longer absolute $(\alpha \neq 1)$ and there is thus some probability of a coup d'état. ${ }^{13}$ When incumbency advantage increases, policies become less stringent. However, suppose the rival can gain a large amount of public support by making its policies more stringent than the incumbent. This increases the probability of a coup d'état. The firm does not want this to occur as 
its profits will be lower under a rival government. As such, it may try to 'payoff' the rival in order to prevent it from adopting these policies by increasing contributions. Note the firm's willingness to corrupt the rival is determined by the difference in profits to be earned under the parties (more willing if this difference is large), the ability of the rival to foster political support (less willing if this is small) and the cost of deterring it from doing so (less willing if this is large).

Corollary 1: Where the political effect of a change in policy is large, the firm may increase contributions to both political parties, even when incumbency advantage means that the rival has a low chance of gaining power. Increases in contributions to the rival are made to impede the political system and keep the more favoured party in power.

\section{Conclusion}

This paper presents a model where a polluting firm can use different forms of corruption to try and minimise the effect of environmental policy. The model follows closely the earlier work of Grossman and Helpman (1994; 1996) and Mookherjee and Png (1995). The focus of the paper is on whether political competition has a role in combating both petty and grand corruption, and if so, under what circumstances is this likely to be the case.

The results suggest that higher levels of political competition will lead to the adoption of more stringent environmental policy and higher fines for evading their effects. Importantly, more stringent policy always reduces emission levels. In this respect, the model suggests political competition to be important in achieving a reduction in environmental damage. However, corruption in all of its forms has the capacity to temper the magnitude of this outcome.

In the case of petty corruption, the firm has an incentive to evade payment of the environmental tax through the use of bribes to induce an inspector to under-report true emission levels. In this one period model, the marginal fine is the only device that

\footnotetext{
${ }^{13}$ In the model, this probability is given by $\left(1-\rho\left(\mathrm{W}^{\mathrm{i}}, \mathrm{W}^{\mathrm{j}}\right)\right)$.
} 
political parties can use to penalise such behaviour. It is shown that while the firm has a stronger incentive to evade higher tax rates induced by greater political accountability, petty corruption will fall provided the enforcement infrastructure is well developed. In particular, it is necessary to have an audit regime which is responsive to the level of reporting and for the punishment regime to be imposed in such a way as to match the severity of the crime. These requirements may take time to adjust and in the event that they are sufficiently weak, petty corruption may rise with political competition.

The effects of political competition on grand corruption are also somewhat ambiguous. The results in the model suggest that this will be largely determined by how large a welfare issue environmental policy is. In particular, if the political effects of policy are large, then grand corruption will fall. However, if the political effect of policy is small, then an increase in political competition may simply see the firm adjust its allocation of payments between the incumbent and opposition parties without decreasing their overall level. Clearly, if the public have little regard for the environment, then political competition has little scope to constrain polluting interests from bribing high level officials to ignore environmental damage. While not modelled here, this notion also extends to the case where a population have a large degree of uncertainty about the effects of pollution. This may be a particular problem in countries where previous regimes have stifled the dissemination of information regarding environmental issues. This leads to the policy implication that in such regimes, introducing more democratic political processes may not be sufficient to reduce grand corruption.

The results presented here also introduce a possibility that polluting interests face incentives to try and stifle the political process. This result is consistent with the 'electoral motive' for making contributions to political parties detailed in Grossman and Helpman (1994). The model suggests that when the political effects of policy are large, the firm may focus its attentions on corrupting any party which attempts to capitalise on public support by adopting more stringent anti-corruption and environmental policy. Thus, while political competition has been shown to reduce 
grand corruption provided the welfare of citizens is affected by policies to a sufficient extent, special interest groups may attempt to undermine the strength of any challengers to their preferred party. In a more general setting, this may indicate that political competition itself may be hard to establish in countries where grand corruption is a feature.

Political competition, as defined in this paper, is a reduction in the incumbent government's ability to ignore the welfare consequences of its policies. A worthwhile extension would be to allow for more complex political systems. There is a vast literature detailing the nature of political competition. The inclusion of a more complex system of political determination may yield interesting results. The model here is also restricted itself to the analysis of an incumbent party and a single rival. A clear extension would be to allow for a larger number of challengers. Similarly, environmental interests may also be represented by special interest groups and could, in the same manner as the firm, attempt to influence policy decisions by making payments to incumbent and rival policies. 


\section{$\underline{\text { References }}$}

Austen-Smith D. (1987), 'Interest Groups, Campaign Contributions, and Probabilistic Voting', Public Choice, 54(2), 123-139

Baron D.P.(1994), 'Electoral Competition with Informed and Uniformed Voters', American Political Science Review, 88, 33-47

Bernheim B. D. and Whinston M. D. (1986), 'Menu Auctions, Resource Allocation and Economic Influence', Quarterly Journal of Economics, 101(1), 1-31.

Erikson R. S. and Palfrey, T. (1993), 'The Puzzle of Incumbent Spending in Congressional Elections', Social Science Working Paper no. 806, Pasadena Inst. of Technology.

Callister D. J., (1999), Corrupt and Illegal Activities in the Forestry Sector, World Bank Discussion Paper, May 1999.

Downs A. (1957), An Economic theory of Democracy, New York, Harper and Row.

Easterly W and Levine R (1997), 'Africa's Growth Tragedy: Policies and Ethnic Divisions', QJE, Nov 1203-1250

Glantz S. A., Abramowitz A. I., and Burkart M. P. (1976), 'Election Outcomes: Whose Money Matters?' J. Politics 38 1033-38

Grossman G. M. and Helpman E. (1994), 'Protection for Sale', American Economic Review, Vol 84, number 4, 833-850

Grossman G. M. and Helpman E. (1996), 'Electoral Competition and Special Interest Politics', Review of Economic Studies, 63, 265-286

Johnston M (1999), Corruption and Democratic Consolidation, Department of Political Science, Colgate University, Hamilton, N.Y.

Levitt S D. (1994), 'Using Repeat Challengers to Estimate the Effect of Campaign Spending on Election Outcomes in the US House', J. Pol. Economy, vol 102, no. 4 p777-798

Mauro P. (1995), 'Corruption and Growth', Quarterly Journal of Economics, 110:68712.

Mookherjee D., and Png I.P.L. (1995), 'Corruptible Law Enforcers: How Should They Be Compensated?', Economic Journal, 105: 145-59

Pope J. (Ed).,(1996), The TI Source Book. Transparency International, Berlin.

Roemer J E (2002), Political Competition, Theory and Applications, Harvard University Press 
Romer T (1975), 'Individual Welfare, Majority Voting, and the Properties of Linear Income Tax', Journal of Public Economics, vol. 4 issue 2, pp 163-85

Rose Ackerman S. (1999), Corruption and Government: Causes, Consequences and Reform, Cambridge University Press

Treisman D. (2000), 'The Causes of Corruption: a Cross National Study', Journal of Public Economics, 76: 399-457

Wei S J (1997), How Taxing is Corruption on Overseas Investors, NBER Working Paper 6030.

World Bank (1997), Helping Countries Combat Corruption: The Role of the World Bank, World Bank, Washington.

World Bank (2000), Anticorruption in Transition: A Contribution to the Policy Debate, World Bank, Washington. 


\section{$\underline{\text { Appendix A }}$}

This section details some useful properties of the equilibrium arising in the firminspector interaction.

Beginning with equations (3a) and (3b), we have

$J_{\hat{e}}=-\mathrm{t}+\lambda \frac{\partial h^{T}(\theta, v)}{\partial v}-\frac{\partial \lambda}{\partial \hat{e}} h(\theta, v)=0$

$J_{e}=\frac{\partial G}{\partial e}-\lambda \frac{\partial h^{T}(v, \theta)}{\partial v}=0$

Total differentiation yields

$\left[\begin{array}{ll}J_{\hat{e} \hat{e}} & J_{\hat{e} e} \\ J_{e \hat{e}} & J_{e e}\end{array}\right]\left[\begin{array}{c}d \hat{e} \\ d e\end{array}\right]=-\left[\begin{array}{c}J_{\hat{\hat{t}}} \\ 0\end{array}\right] d t-\left[\begin{array}{l}J_{\hat{e} \theta} \\ J_{e \theta}\end{array}\right] d \theta$

where

$$
\begin{aligned}
& J_{\hat{e} e}=J_{e \hat{e}}=\lambda \frac{\partial^{2} h}{\partial v^{2}}-\frac{\partial \lambda}{\partial \hat{e}} \frac{\partial h}{\partial v}>0 \\
& J_{\hat{\mathrm{et}}}=-1 \\
& J_{\hat{e} \hat{e}}=2\left(\frac{\partial \lambda}{\partial \hat{e}} \frac{\partial h}{\partial v}\right)-\frac{\partial^{2} \lambda}{\partial \hat{e}^{2}} h(\theta, v)-\lambda \frac{\partial^{2} h}{\partial v^{2}}<0 \\
& J_{e e}=\frac{\partial^{2} G}{\partial e^{2}}-\lambda \frac{\partial^{2} h}{\partial v^{2}}<0
\end{aligned}
$$


$J_{e e}<0, \quad J_{\hat{e} \hat{e}}<0, \quad\left|J_{e e}\right|>\left|J_{e \hat{e}}\right|$ and $\left|J_{\hat{e} \hat{e}}\right|>\left|J_{e \hat{e}}\right|^{14}$, ensuring a unique and stable solution. This ensures the determinant of the coefficient matrix, defined as

$\Delta=J_{\hat{e} \hat{e}} J_{e e}-J_{\hat{e} e}{ }^{2}$ is positive.

$J_{\hat{e} \theta}=-\frac{\partial \lambda}{\partial \hat{e}} \frac{\partial h}{\partial \theta}+\lambda \frac{\partial^{2} h}{\partial v \partial \theta}>0 \quad ; \quad J_{e \theta}=-\lambda \frac{\partial^{2} h}{\partial \nu \partial \theta}<0$

\section{Property 1}

$\frac{d \hat{e}}{d t}=\frac{-J_{\hat{e} t} J_{e e}}{\Delta}=\frac{J_{e e}}{\Delta}$

As $J_{e e}<0$,

$\frac{d \hat{e}}{d t}<0$

\section{Property 2}

$\frac{d e}{d t}=\frac{J_{\hat{e} t} J_{e \hat{e}}}{\Delta}$

As already noted, $J_{\hat{e} e}>0$ and $\mathrm{J}_{\hat{e} t}=-1$, thus,

$\frac{d e}{d t}<0$

\section{Property 3}

$\frac{d v}{d t}=\frac{d e}{d t}-\frac{d \hat{e}}{d t}=\frac{-\left(J_{e \hat{e}}+J_{e e}\right)}{\Delta}$

${ }^{14}\left|J_{e e}\right|>\left|J_{\hat{e} e}\right|$ requires $\left|\partial^{2} G / \partial e^{2}\right|>|\partial \lambda / \partial \hat{e} \partial h / \partial v|$ which is assumed. 
As $\left|J_{e \hat{e}}\right|<\left|J_{e e}\right|$,

$\frac{d v}{d t}>0$

\section{Property 4}

$\frac{d \hat{e}}{d \theta}=\frac{J_{e \theta} J_{\hat{e} e}-J_{\hat{e} \theta} J_{e e}}{\Delta}>0$

as $\left|J_{e \theta}\right|<\left|J_{\hat{e} \theta}\right|$ and $\left|J_{e e}\right|>\left|J_{\hat{e} e}\right|$

$\frac{d \hat{e}}{d \theta}>0$

\section{Property 5}

$\frac{d e}{d \theta}=\frac{J_{e \hat{e}} J_{\hat{e} \theta}-J_{\hat{e} \hat{e}} J_{e \theta}}{\Delta}<0$

It is assumed that $\left|J_{\hat{e} \hat{e}}\right|>\left|J_{e \hat{e}}\right|$ by a sufficient amount to ensure

$\left|J_{\hat{e} \hat{e}} J_{e \theta}\right|>\left|J_{e \hat{e}} J_{\hat{e} \theta}\right|$, thus

$\frac{d e}{d \theta}<0$

\section{Property 6}

$\frac{d v}{d \theta}=\frac{d e}{d \theta}-\frac{d \hat{e}}{d \theta}=\frac{J_{\hat{e} \theta}\left(J_{e e}+J_{e \hat{e}}\right)-J_{e \theta}\left(J_{\hat{e} \hat{e}}+J_{\hat{e} e}\right)}{\Delta}<0$

which follows directly from the properties (4) and (5) 


\section{$\underline{\text { Appendix B }}$}

Using (9a) and (9b), and substituting $\partial S / \partial \Phi$ from (10c) and (10d), we obtain the following first order conditions:

$Z_{i}=(\alpha+(1-\alpha) \rho) \frac{\partial \Pi^{i}}{\partial \Phi^{i}}+(1-\alpha) \frac{\partial \rho}{\partial W^{i}} \frac{\partial W^{i}}{\partial \Phi^{i}}\left(\Pi^{i}-\Pi^{j}+R\right)=0 \quad \Phi=t, \theta$

$Z_{j}=[1-(\alpha+(1-\alpha) \rho)] \frac{\partial \Pi^{j}}{\partial \Phi^{j}}+(1-\alpha) \frac{\partial \rho}{\partial W^{j}} \frac{\partial W^{j}}{\partial \Phi^{j}}\left(\Pi^{i}-\Pi^{j}-R\right)=0 \quad \Phi=t, \theta$

Totally differentiating the above system of equations yields

$\left[\begin{array}{cc}Z_{i i}{ }^{i} & Z_{i j}{ }^{i} \\ Z_{j i}{ }^{j} & Z_{j j}{ }^{j}\end{array}\right]\left[\begin{array}{l}d \Phi^{i} \\ d \Phi^{j}\end{array}\right]=-\left[\begin{array}{c}Z_{i \alpha}{ }^{i} \\ Z_{j \alpha}{ }^{j}\end{array}\right] d \alpha \quad \Phi=t, \theta$

For the existence of an unique, stable solution, it is assumed that: $Z_{i i}{ }^{i}<0, Z_{j j}{ }^{j}<0 ;\left|Z_{i i}{ }^{i}\right|>\left|Z_{i j}{ }^{i}\right|,\left|Z_{i i}{ }^{i}\right|>\left|Z_{j i}{ }^{j}\right|,\left|Z_{j j}{ }^{j}\right|>\left|Z_{j i}{ }^{j}\right| \quad$ and $\left|Z_{j j}{ }^{j}\right|>\left|Z_{i j}{ }^{i}\right|$

These conditions also assure that the determinant of the coefficient matrix is positive:

$\Omega=Z_{i i}{ }^{i} Z_{j j}{ }^{j}-Z_{j i}{ }^{j} Z_{i j}{ }^{i}>0$

Note also,

$$
\begin{aligned}
& \frac{\partial \Pi}{\partial t}=-\hat{e}<0 \\
& \frac{\partial \Pi}{\partial \theta}=-\lambda \frac{\partial h}{\partial \theta}<0 \\
& \frac{\partial W}{\partial t}=\left(P-\frac{\partial D}{\partial e}\right) \frac{\partial e}{\partial t}>0 \\
& \frac{\partial W}{\partial \theta}=\left(P-\frac{\partial D}{\partial e}\right) \frac{\partial e}{\partial \theta}-\frac{\partial C}{\partial \theta}>0
\end{aligned}
$$




\section{Lemma 1}

1. $\quad \frac{d \Phi^{i}}{d \alpha}=\frac{-Z_{i \alpha}{ }^{i} Z_{j j}{ }^{j}+Z_{j \alpha}{ }^{j} Z_{i j}{ }^{i}}{\Omega}$

$$
\Phi=t, \theta
$$

Where,

$Z_{i \alpha}{ }^{i}=(1-\rho) \frac{\partial \Pi^{i}}{\partial \Phi^{i}}-\frac{\partial \rho}{\partial W^{i}} \frac{\partial W^{i}}{\partial \Phi^{i}}\left(\Pi^{i}-\Pi^{j}+R\right)<0$ when $\mathrm{R}>\Pi^{\mathrm{i}}-\Pi^{\mathrm{j}} .^{15}$

$Z_{j \alpha}^{j}=-(1-\rho) \frac{\partial \Pi^{j}}{\partial \Phi^{j}}-\frac{\partial \rho}{\partial W^{j}} \frac{\partial W^{j}}{\partial \Phi^{j}}\left(\Pi^{i}-\Pi^{j}-R\right)<0$

Again, $\mathrm{R}$ is assumed to be sufficiently large to ensure that the above inequality holds.

and,

$Z_{i j}{ }^{i}=Z_{j i}{ }^{j}=(1-\alpha) \frac{\partial \Pi^{i}}{\partial \Phi^{i}} \frac{\partial \rho}{\partial W^{j}} \frac{\partial W^{j}}{\partial \Phi^{j}}-(1-\alpha) \frac{\partial \rho}{\partial W^{i}} \frac{\partial W^{i}}{\partial \Phi^{i}} \frac{\partial \Pi^{j}}{\partial \Phi^{j}}>0$

thus,

$\frac{d t^{i}}{d \alpha}<0$

and

$\frac{d \theta^{i}}{d \alpha}<0$

2. $\frac{d \Phi^{j}}{d \alpha}=\frac{-Z_{i i}{ }^{i} Z_{j \alpha}{ }^{j}+Z_{j i}{ }^{j} Z_{i \alpha}{ }^{i}}{\Omega}$

$\Phi=t, \theta$

As noted, $Z_{j \alpha}{ }^{j}<0 \quad Z_{i \alpha}{ }^{i}<0$ and $Z_{j i}{ }^{j}>0$. Thus,

$\frac{d t^{j}}{d \alpha}<0 \quad \frac{d \theta^{j}}{d \alpha}<0$

${ }^{15}$ It is assumed in this paper that profits of the firm are smaller than the exogenous gains earned by those holding political power. 
3. The change in the tax rate induced by a change in incumbency advantage may be greater than that of the marginal fine if costs associated with the latter are large, $|d t / d \alpha|>|d \theta / d \alpha|$

From the first order conditions of the two political parties (A2) and (A3), it is evident that the only motivation to adopt welfare maximising policies is for political gain. The size of any such gain depends on the improvement in aggregate welfare which occurs as a result of the policy change. In the event that auditing costs are large, the welfare effects of an increase in the marginal fine are diluted. When political competition increases (i.e. a reduction in $\alpha$ ), the political parties will increase the stringency of policy in order to improve their chances of winning the political struggle. Taking the case of the incumbent government and using equations (7a) and (7b), the change in political support for a change in the tax rate can be written as: ${ }^{16}$

$\frac{\partial \rho}{\partial t^{i}}=\left[\left(P-\frac{\partial D}{\partial e}\right) \frac{\partial e}{\partial t^{i}}\right] \frac{\partial \rho}{\partial W^{i}}>0$

and

$\frac{\partial \rho}{\partial \theta^{i}}=\left[\left(P-\frac{\partial D}{\partial e}\right) \frac{\partial e}{\partial \theta^{i}}-\frac{\partial C}{\partial \theta}\right] \frac{\partial \rho}{\partial W^{i}}>0$

When $\partial C / \partial \theta$ is very large, the magnitude of equation (A8) falls relative to (A7). As such, the tax is the more effective policy to reduce emissions and thus improve welfare. Ceteris paribus, the tax rate will be more responsive to changes in the level of political competition.

\footnotetext{
${ }^{16}$ The results hold equally for the case of the rival party
} 


\section{Lemma 2}

An increase in political competition results in a decrease in the level of emissions and thus brings about better environmental outcomes, $\quad \frac{d e}{d \alpha}<0$.

From properties 2 and $5, \quad d e / d t<0$ and $d e / d \theta<0$.

$d t / d \alpha<0$ and $d \theta / d \alpha<0($ Lemma 1$))$, an increase in political competition will increase the stringency of these policy parameters adopted by either political party. As a result, an increase in political competition (decrease in $\alpha$ ) will result in lower emission levels.

\section{Lemma 3}

When political competition increases, the effect on under-reporting is ambiguous:

$$
\frac{d v}{d \alpha}<0
$$

Note that Properties (3) and (6) reveal:

$$
\begin{aligned}
& \frac{d v}{d t}>0 \\
& \frac{d v}{d \theta}<0
\end{aligned}
$$

As increased political competition results in an increase in the tax rate and the marginal fine, the overall effect on under-reporting will depend on two factors:

I. The relative magnitude of $\frac{d v}{d t}$ and $\frac{d v}{d \theta}$. 
II. The change in the marginal fine relative to the tax rate, given a change in political competition $(\alpha)$.

I. The relative magnitude of $\frac{d v}{d t}$ and $\frac{d v}{d \theta}$.

Comparing the results from Properties (3) and (6):

$\frac{d v}{d t}=\frac{-\left(J_{e \hat{e}}+J_{e e}\right)}{\Delta}<0$

$\frac{d v}{d \theta}=\frac{J_{\hat{e} \theta}\left(J_{e e}+J_{e \hat{e}}\right)-J_{e \theta}\left(J_{\hat{e} \hat{e}}+J_{\hat{e} e}\right)}{\Delta}<0$

Examining these equations, it is evident that $\left|\frac{d v}{d t}\right|>\left|\frac{d v}{d \theta}\right|$ is only possible when $\left|J_{e \theta}\right|$ and $\left|J_{\hat{e} \theta}\right|$ are very small in size. This occurs when $\left|\frac{\partial \lambda}{\partial \hat{e}} \frac{\partial h}{\partial v}\right|$ and $\lambda \frac{\partial^{2} h}{\partial \nu \partial \theta}$ are both small in magnitude. For instance, suppose that both of these terms approach zero. This implies the change in under-reporting given a change in emissions will also be close to zero. Performing relevant substitutions for $J_{e \hat{e}}$ and $J_{e e}$, we get,

$\frac{d v}{d t}=\frac{-\left(\frac{\partial^{2} G}{\partial e^{2}}-\frac{\partial \lambda}{\partial \hat{e}} \frac{\partial h}{\partial v}\right)}{\Delta}>0 \quad$ iff $\quad\left|\frac{\partial^{2} G}{\partial e^{2}}\right|>\left|\frac{\partial \lambda}{\partial \hat{e}} \frac{\partial h}{\partial v}\right|$

as $\frac{\partial \lambda}{\partial \hat{e}} \frac{\partial h}{\partial v} \rightarrow 0 \quad \frac{d v}{d t}=-\frac{\partial^{2} G}{\partial e^{2}}>0$

while under the same circumstances, 
$\frac{d v}{d \theta} \rightarrow 0$

Thus, where enforcement mechanisms are very weak, an increase in political competition may increase petty corruption.

\section{The change in the marginal fine relative to the tax rate, given a change in} political competition $(\alpha)$.

As noted in lemma 1, the change in the marginal rate of taxation and fines turns on the welfare effects of each policy. When the marginal costs associated with implementing a fine is large, the welfare effects of a change are diluted and the government relies on taxation.

Another important determinant of the welfare effect derived from each policy instrument is the effect on emission levels. Obviously, an increase in either the tax or the fine will only increase welfare when emission levels are reduced. The effects on emissions from and increase in the tax and the fine are given by properties 2 and 5:

$$
\begin{aligned}
& \frac{d e}{d t}=\frac{-J_{e \hat{e}}}{\Delta}<0 \\
& \frac{d e}{d \theta}=\frac{J_{e \hat{e}} J_{\hat{e} \theta}-J_{\hat{e} \hat{e}} J_{e \theta}}{\Delta}<0
\end{aligned}
$$

Again, if $\left|J_{e \theta}\right|$ and $\left|J_{\hat{e} \theta}\right|$ are sufficiently small, $\left|\frac{d e}{d t}\right|>\left|\frac{d e}{d \theta}\right|$. This will mean that the political incentive to increase the marginal fine will be lower (cet. par.). Note that when $\left|J_{e \theta}\right|$ and $\left|J_{\hat{e} \theta}\right|$ are sufficiently small, we also get $\left|\frac{d v}{d t}\right|>\left|\frac{d v}{d \theta}\right|$. Again, this occurs when $\lambda$ and $\partial \lambda / \partial \hat{e}$ are small. This re-enforces the notion that weak enforcement acts as a barrier to the reduction of petty corruption. 


\section{Contributions}

Equations (10a) and (10b) are as follows:

$$
\begin{aligned}
& F_{i}=(\alpha+(1-\alpha) \rho) \frac{\partial \Pi^{i}}{\partial \Phi^{i}} \frac{\partial \Phi^{i}}{\partial S^{i}}+(1-\alpha) \frac{\partial \rho}{\partial W^{i}} \frac{\partial W^{i}}{\partial \Phi^{i}} \frac{\partial \Phi^{i}}{\partial S^{i}}\left(\Pi^{i}-\Pi^{j}\right)-1=0 \\
& F_{j}=[1-(\alpha+(1-\alpha) \rho)] \frac{\partial \Pi^{j}}{\partial \Phi^{j}} \frac{\partial \Phi^{j}}{\partial S^{j}}+(1-\alpha) \frac{\partial \rho}{\partial W^{j}} \frac{\partial W^{j}}{\partial \Phi^{j}} \frac{\partial \Phi^{j}}{\partial S^{j}}\left(\Pi^{i}-\Pi^{j}\right)-1=0
\end{aligned}
$$

Totally differentiating the system and writing in matrix notation, we get

$\left[\begin{array}{cc}F_{i i}{ }^{i} & F_{i j}{ }^{i} \\ F_{j i}{ }^{j} & F_{j j}{ }^{j}\end{array}\right]\left[\begin{array}{l}d S^{i} \\ d S^{j}\end{array}\right]=-\left[\begin{array}{c}F_{i \alpha}{ }^{i} \\ F_{j \alpha}{ }^{j}\end{array}\right] d \alpha$

Again, for an unique and stable solution, it is assumed that:

$F_{i i}{ }^{i}<0, F_{j j}{ }^{j}<0 ;\left|F_{i i}{ }^{i}\right|>\left|F_{i j}{ }^{i}\right|,\left|F_{i i}{ }^{i}\right|>\left|F_{j i}{ }^{j}\right| \quad,\left|F_{j j}{ }^{j}\right|>\left|F_{j i}{ }^{j}\right|$ and $\left|F_{j j}{ }^{j}\right|>\left|F_{i j}{ }^{i}\right|$

\section{Proposition 1a}

When environmental damage is a sufficiently large welfare issue, the firm will make greater contributions to the party it would least prefer to see in power.

When environmental damage is large, equations (7a) and (7b) reveal that $\partial W / \partial \Phi$ is large. Examining equations (10c) and (10d):

$$
\begin{aligned}
& \frac{\partial S^{i}}{\partial \Phi^{i}}=(\alpha+(1-\alpha) \rho) \frac{\partial \Pi^{i}}{\partial \Phi^{i}}+(1-\alpha) \frac{\partial \rho}{\partial W^{i}} \frac{\partial W^{i}}{\partial \Phi^{i}}\left(\Pi^{i}-\Pi^{j}\right) \\
& \frac{\partial S^{j}}{\partial \Phi^{j}}=[1-(\alpha+(1-\alpha) \rho)] \frac{\partial \Pi^{j}}{\partial \Phi^{j}}+(1-\alpha) \frac{\partial \rho}{\partial W^{j}} \frac{\partial W^{j}}{\partial \Phi^{j}}\left(\Pi^{i}-\Pi^{j}\right)
\end{aligned}
$$

Note that for positive contributions (10c) and (10d) must be less than zero. If this is not the case, an increase in contributions does not secure a more favourable policy outcome and there is no incentive for the firm to give money. 
$\underline{\text { Case } 1-\Pi^{i}-\Pi^{j}>0}$

Suppose that environmental damage is a large welfare issue such that

$$
\frac{\partial W}{\partial \Phi} \rightarrow \infty
$$

Substituting into (10c) and (10d), we get:

$$
\begin{array}{lll}
\frac{\partial S^{i}}{\partial \Phi^{i}} \rightarrow+\infty & \Rightarrow & S^{i}=0 \\
\frac{\partial S^{j}}{\partial \Phi^{j}} \rightarrow-\infty & \Rightarrow & S^{j}>0
\end{array}
$$

$\underline{\text { Case } 2-\Pi^{i}-\Pi^{j}<0}$

For $\frac{\partial W}{\partial \Phi} \rightarrow \infty$

$\frac{\partial S^{i}}{\partial \Phi^{i}} \rightarrow-\infty \quad \Rightarrow \quad S^{i}>0$

$\frac{\partial S^{j}}{\partial \Phi^{j}} \rightarrow+\infty \quad \Rightarrow \quad S^{j}=0$

\section{Proposition $1 b$}

For the proof of this proposition, it is assumed that $\Pi^{i}-\Pi^{j}>0$ as detailed in the text.

$$
\begin{aligned}
& \frac{d S^{i}}{d \alpha}=\frac{-F_{i \alpha}{ }^{i} F_{j j}{ }^{j}+F_{j \alpha}{ }^{j} F_{i j}{ }^{i}}{\Omega} \\
& F_{i \alpha}{ }^{i}=\left[(1-\rho) \frac{\partial \Pi^{i}}{\partial \Phi^{i}}-\frac{\partial \rho}{\partial W^{i}} \frac{\partial W^{i}}{\partial \Phi^{i}}\left(\Pi^{i}-\Pi^{j}\right)\right] \frac{\partial \Phi^{i}}{\partial S^{i}}>0
\end{aligned}
$$




$$
F_{j \alpha}^{j}=\left[(\rho-1) \frac{\partial \Pi^{j}}{\partial \Phi^{j}}+\frac{\partial \rho}{\partial W^{j}} \frac{\partial W^{j}}{\partial \phi^{j}}\left(\Pi^{i}-\Pi^{j}\right)\right] \frac{\partial \Phi^{j}}{\partial S^{j}}<0
$$

Notice that the first term in parenthesis of equation (A10) is positive, while the second term is negative. The sign of $F_{j \alpha}{ }^{j}$ thus depends on the absolute magnitude of each term.

$$
{F_{i j}}^{i}=F_{j i}{ }^{j}=(1-\alpha) \frac{\partial \rho}{\partial W^{j}} \frac{\partial W^{j}}{\partial \Phi^{j}} \frac{\partial \Phi^{j}}{\partial S^{j}} \frac{\partial \Pi^{i}}{\partial \Phi^{i}} \frac{\partial \Phi^{i}}{\partial S^{i}}-(1-\alpha) \frac{\partial \rho}{\partial W^{i}} \frac{\partial W^{i}}{\partial \Phi^{i}} \frac{\partial \Phi^{i}}{\partial S^{i}} \frac{\partial \Pi^{j}}{\partial \Phi^{j}} \frac{\partial \Phi^{j}}{\partial S^{j}}>0
$$

It is assumed that $\left|F_{j j}{ }^{j}\right|>\left|F_{i j}{ }^{i}\right|$ by a sufficient amount to ensure that the first term dominates. Thus,

$$
\begin{aligned}
& \frac{d S^{i}}{d \alpha}>0 \\
& \frac{d S^{j}}{d \alpha}=\frac{-F_{i i}{ }^{i} F_{j \alpha}{ }^{j}+F_{j i}{ }^{j} F_{i \alpha}{ }^{i}}{\Omega}
\end{aligned}
$$

As already shown, the sign of $F_{j \alpha}{ }^{j}$, and therefore the first term in (A11) is ambiguous. The second term is unambiguously positive.

Thus, $\frac{d S^{j}}{d \alpha}<0$

The sign depends on the relative sizes of the terms in parenthesis in (A10). These are defined as follows:

$$
\begin{aligned}
& \Gamma=\left|\frac{\partial \Pi^{j}}{\partial \Phi^{j}}(\rho-1)\right| \equiv \text { Marginal cost of changing policy }{ }^{17} \\
& \Sigma=\left|\frac{\partial \rho}{\partial W^{j}} \frac{\partial W^{j}}{\partial \Phi^{j}}\left(\Pi^{i}-\Pi^{j}\right)\right| \equiv \text { Marginal political effect }
\end{aligned}
$$


When $\Gamma>\Sigma$,

$\frac{d S^{j}}{d \alpha}<0$

and when $\Gamma<\Sigma$,

$\frac{d S^{j}}{d \alpha}>0$

${ }^{17}$ Note that an increase in $\partial \Pi / \partial \Phi$ can be interpreted as an increase in the cost of obtaining a policy change as part of the local truthfulness condition. 